\title{
CASE STUDY REGARDING THE INTERESTS AND LEISURE PRACTICES OF PERSONS AGED 50 AND OVER IN SAINT-LÉONARD, SUBURB OF MONTREAL: SENIORS VS. BABY BOOMERS
}

\author{
ROMAIN ROULT ${ }^{1}$, HÉLÈNE CARBONNEAU ${ }^{1}$, JEAN-MARC ADJIZIAN ${ }^{2}$, ÉMILIE BELLEY-RANGER 3 , \\ MARIE-MICHÈLE DUQUETTE ${ }^{3}$ \\ ${ }^{1}$ University of Quebec in Trois-Rivières, Department of Leisure Studies, Culture and Tourism \\ ${ }^{2} \mathrm{PhD}$ Studies, University of Ottawa, School of Human Kinetics \\ ${ }^{3}$ PhD Studies, University of Quebec in Trois-Rivières, Department of Psychology
}

\author{
Mailing address: Romain Roult, University of Quebec in Trois-Rivières, Department of Leisure Studies, \\ Culture and Tourism, 3351 des Forges Boulevard, C.P. 500, Trois-Rivières (Québec) G9A 5H7, tel.: +1 819 3765011, \\ ext. 3286, fax: +1 819 3765158, e-mail: romain.roult@uqtr.ca
}

\begin{abstract}
Introduction. Several studies have shown that leisure contributes to improving seniors' quality of life. However, some of this research has also highlighted the fact that there are marked physical, socioeconomic, and cultural disparities in this population. Material and methods. To this end, this article presents the results of a survey conducted in 2015 in Montreal with 464 respondents aged 50 and over regarding their interests and leisure practices. Results. This study highlights the importance that persons in this age group give to physical and outdoor recreation as well as free and outdoor activities. However, this study has also confirmed that there exist, regarding the problem of leisure, more or less significant differences among seniors and baby boomers which need to be taken into account by local actors. Conclusions. The results obtained and the correlated analyses clearly indicate that the senior population is not homogeneous with respect to their practices and their leisure needs. This analytical finding confirms that leisure and community services must be planned, programmed, and promoted taking into account these generational differences, as well as physical, socioeconomic, and cultural differences.
\end{abstract}

Key words: public leisure, seniors, leisure interests, recreational practices, Montreal

\section{Introduction}

The fact that the population is ageing is no longer in doubt. In recent years, the influx of baby boomers at age 65 has accelerated this process [1]. According to the Statistical Institute of Quebec [2], the percentage of people aged 65 and over in Quebec should increase from $15.7 \%$ in 2011 to $28.5 \%$ in 2061 . This reality is calling out to several actors who are helping support older people in making the ageing process as harmonious as possible. The municipal sector is expected to play an important role in providing community services and leisure to this clientele, since the vast majority of seniors (96.3\%) live and grow old at home, therefore, within their community.

In the Quebec government's policy 'To age and live at home', three directives are described specifying that 'Aging and living together' is: 1) participating in the community;2) healthy living in the community; and 3) creating healthy, safe, and welcoming environments in the community [1]. Maintaining social participation is essential for promoting active ageing [3]. Social participation refers here to various activities (social, leisure, work, and volunteering) that lead individuals to actively participate in the life of their community. With respect to seniors, several studies show that leisure contributes significantly to improving the quality of life of this clientele $[4,5,6,7]$. As such, Riddick and Daniel [8] state that participation in leisure would be decisive for psychological well-being. Furthermore, various studies show that participation in leisure contributes to the maintenance of good mental and physical health $[9,10,11]$. However, it should also be noted that while participation promotes successful ageing, the quality more than quantity of activities is important to consider in this perspective [7]. This indicates the importance of better understanding the determinants of the quality of seniors' leisure experience.

Alongside these proposals, talking about seniors as a homogeneous population is a mistake in itself and has led several authors to say that adopting this vision can cause significant problems when it comes time for leisure professionals to plan and implement their programming [12, 13, 14]. Roberts [15] and Murphy Jr et al. [16], based on Mannheim and Rokeach's theoretical work, indicate that this class of seniors would consist, in an overall consensus, of two generations, namely seniors (born before 1946) and baby boomers (born between 1946 and 1966). In view of the interests and leisure practices of these two generations, several studies also evoke more or less marked differences. While seniors generally have a fairly large social circle and engage in volunteer and socio-cultural activities, baby boomers are more interested in individual leisure activities enjoyed alone or with family and close friends [13, 16, 17]. Kim et al. [18], Sperazza and Banergee [14], and Ziegler [19] go even further by stipulating that seniors usually practise activities related to their age, and often more sedentary, while baby boomers aspire to find different forms of experience or take risks in their leisure 
time, which brings them to opt for activities not necessarily intended for them from the start. These findings led Beauchamp and Marcotte [12] and Fitzpatrick and McCabe [20] to state that public leisure as well as private offers of leisure must be planned and programmed, taking into account these ideas of leisure and thus the different needs of these two groups.

Therefore, leisure activity is an important component of this social participation. It is highly important to better understand the impacts of leisure activity and find ways to better meet the needs of seniors in terms of offering recreational activities conducive to active ageing. It is this issue that the current study is based on. In 2015, Saint-Léonard commissioned a team of researchers from the University of Quebec in Trois-Rivières (UQTR) to assess the recreational needs of the resident population aged 50 and over. For the purposes of this article, we will discuss some aspects of this study, namely those related to leisure interests and practices, communication strategies to reach this population, and the perceived constraints. Beyond these very descriptive objectives, this study also aimed to see if the physical, economic, social, and cultural disparities exist in the general population aged 50 years and older that was surveyed. Finally, the broader objective of this study was to reflect, view the results, and look at ways to adapt municipal services in order to encourage and facilitate the social, economic, and cultural life of seniors in their living environments. A general research hypothesis was formulated at the beginning of this project: interest and level of practice in leisure differs between the babyboomer clientele and seniors and requires a better adaptation of community services and leisure offered by the district.

\section{Material and methods}

The data collection method used is based on a quantitative approach via a survey by questionnaire. The questionnaire was developed from elements from the survey conducted by Carbonneau in 2011 [21] which aimed to create a portrait of leisure practices in Quebecers 50 years of age and older. The questionnaire used in the study in Saint-Léonard was structured around six sections of questions:

1. interest in and practice of leisure activities,

2. terms of practice,

3. constraints to participation,

4. satisfaction related to the leisure offer,

5. priorities for the development of leisure,

6. personal and social data of respondents.

Overall, respondents were asked 43 questions. It is to be noted that three questions were short-answer, giving the respondents the opportunity to express certain ideas and other suggestions. Beyond these questions, respondents could also, for some issues, propose a different answer from those suggested, via the answer choice 'Other'. The average length of time it took each respondent to complete the survey was 20 minutes.

This questionnaire was administered in person by a dozen investigators between $16^{\text {th }}$ June and $22^{\text {nd }}$ August, 2015, to residents of Saint-Léonard aged 50 years and older. A total of 17 data collection days were organised in this area. Each session lasted seven hours and took place in parks, via door-to-door interviews in homes and targeted, low-income housing (HLM), and in businesses or commercial stores. A total of 464 people responded and participated in the survey. Regarding data analysis, SPSS software was used to calculate the descriptive statistics, cross-reference the variables, and perform some statistical tests.

\section{Results}

The section gives an overview of the results of the study. It is important to note that the results presented are weighted according to the statistical picture of the district from the 2011 census.

\section{Profile of respondents}

The distribution of men and women in the sample was approximately equal ( $51.2 \%$ vs. $48.8 \%$, respectively). With regard to age, the sample was distributed as follows: $31.9 \%$ of respondents were aged $50-59$ years, $27.7 \%$ were aged $60-69$ years, $25.4 \%$ were $70-79$ years of age, and 15\% were 80 years and older. Furthermore, over half of respondents did not have post-secondary degrees. It was also noted that the vast majority of respondents (71.1\%) were either married or were in de facto relationships. Almost half of the sample spoke Italian as their first language (45.5\%) and one-third spoke French (32.2\%).

For the question 'Are you currently on the job market?', more than half of respondents $(64.7 \%)$ said they were not, versus close to one-third (31.1\%) who were. With regard to those who said they were not working, almost all were retired (63.5\%), whereas a small percentage of respondents $(1.2 \%)$ said they were not on the job market due to disability. A small majority stated that they worked full time $(18 \%)$ or part time $(8.5 \%)$, while $2.4 \%$ were on sick leave, and $2.2 \%$ were receiving unemployment insurance benefits. Among participants who responded to the question concerning family income, who accounted for half $(58.4 \%)$ of the sample, over a third (38.5\%) said they had a total annual income, before deductions, of between $\$ 10,000$ and $\$ 49,000$. Finally, the people surveyed lived mostly in private homes $(63.2 \%)$.

\section{Leisure interests and practices}

Even though no significant difference emerged for the overall levels of interests and practices, there were some differences in certain practices (tab. 1). Sports and physical activity were considerably more appealing to baby boomers than to seniors $(p \leq 0.013)$. The same conclusion can be drawn for the level of practice $(\mathrm{p} \leq 0.028)$. Moreover, seniors showed interest $(\mathrm{p} \leq 0.000)$ and a level of practice $(\mathrm{p} \leq 0.000)$ significantly higher than baby boomers in games and entertainment. Furthermore, there was a noteworthy difference between the two groups in terms of interest in outdoor activities ( $p \leq 0.017)$, without this being translated into levels of practice $(p \leq 0.213)$, although there was a higher percentage of baby boomers $(37 \%$ versus $27 \%$ ) who reported performing such activities daily.

\section{Perceived constraints}

Data show several significant differences in terms of constraints (tab. 2), with the seniors apparently having greater ones. Functional, emotional, and accessibility-related constraints stood out among the various types of constraints observed. Boomers tended to have more obligation constraints than seniors ( $\mathrm{p} \leq 0.031$ ). This result must be considered with caution given the large number of variables. It is more appropriate to retain a significance level of 0.01 than 0.05 . Interestingly, no difference was noted for organisational and material constraints.

\section{Information channels}

The ways considered most useful for transmitting information regarding the recreational offers revolved around three main information channels. First, the district newspaper 'Le Progrès', was deemed useful by the majority (70.3\%) of the sample. 
Table 1. Comparison of leisure interests and practices: baby boomers vs. seniors

\begin{tabular}{|c|c|c|c|c|}
\hline \multicolumn{2}{|c|}{ Variables } & Baby boomers & Seniors & $p$ \\
\hline \multicolumn{2}{|l|}{ Overall level of leisure interests } & $1.38( \pm 0.53)$ & $1.32( \pm 0.53)$ & $0.21^{*}$ \\
\hline \multicolumn{2}{|l|}{ Overall level of leisure practice } & $1.15( \pm 0.48)$ & $1.15( \pm 0.49)$ & $0.97^{*}$ \\
\hline \multirow{4}{*}{$\begin{array}{l}\text { Interests in physical and sports } \\
\text { activities }\end{array}$} & Very uninterested & 41 & 41 & \multirow{4}{*}{$0.013^{* *}$} \\
\hline & Somewhat uninterested & 32 & 30 & \\
\hline & Somewhat interested & 50 & 38 & \\
\hline & Very interested & 153 & 74 & \\
\hline \multirow{4}{*}{$\begin{array}{l}\text { Practice level of physical and sports } \\
\text { activities }\end{array}$} & Never & 51 & 54 & \multirow{4}{*}{$0.028^{* *}$} \\
\hline & Sometimes & 60 & 43 & \\
\hline & 2-5 times a week & 57 & 33 & \\
\hline & Almost every day & 109 & 57 & \\
\hline \multirow{4}{*}{ Interests in games and entertainment } & Very uninterested & 149 & 74 & \multirow{4}{*}{$0.000^{* *}$} \\
\hline & Somewhat uninterested & 45 & 24 & \\
\hline & Somewhat interested & 47 & 31 & \\
\hline & Very interested & 34 & 55 & \\
\hline \multirow{4}{*}{$\begin{array}{l}\text { Practice level of games and } \\
\text { entertainment }\end{array}$} & Never & 159 & 80 & \multirow{4}{*}{$0.000^{* *}$} \\
\hline & Sometimes & 60 & 28 & \\
\hline & $2-5$ times a week & 42 & 34 & \\
\hline & Almost every day & 15 & 44 & \\
\hline \multirow{4}{*}{$\begin{array}{l}\text { Interests in nature and outdoor } \\
\text { activities }\end{array}$} & Very uninterested & 38 & 38 & \multirow{4}{*}{$0.017^{* *}$} \\
\hline & Somewhat uninterested & 27 & 31 & \\
\hline & Somewhat interested & 79 & 40 & \\
\hline & Very interested & 129 & 76 & \\
\hline \multirow{4}{*}{$\begin{array}{l}\text { Practice level of nature and outdoor } \\
\text { activities }\end{array}$} & Never & 52 & 43 & \multirow{4}{*}{$0.218^{* *}$} \\
\hline & Sometimes & 54 & 44 & \\
\hline & $2-5$ times a week & 66 & 45 & \\
\hline & Almost every day & 103 & 53 & \\
\hline
\end{tabular}

* T test; ** Chi-square test.

Table 2. Comparison of perceived constraints: baby-boomers vs. seniors

\begin{tabular}{|c|c|c|c|c|}
\hline & Variables & Baby-boomers & Seniors & $p^{*}$ \\
\hline \multicolumn{2}{|c|}{ Overall level of leisure constraints } & $0.21( \pm 0.28)$ & $0.37( \pm 0.42)$ & 0.000 \\
\hline \multirow{3}{*}{ Personal constraints } & Functional constraints & $0.17( \pm 0.45)$ & $0.47( \pm 0.62)$ & 0.000 \\
\hline & Emotional constraints & $0.17( \pm 0.34)$ & $0.42( \pm 0.57)$ & 0.000 \\
\hline & Knowledge constraints & $0.24( \pm 0.41)$ & $0.39( \pm 0.61)$ & 0.004 \\
\hline \multirow{5}{*}{ External constraints } & Social constraints & $0.11( \pm 0.38)$ & $0.25( \pm 0.53)$ & 0.002 \\
\hline & Constraints related to obligations & $0.49( \pm 0.66)$ & $0.35( \pm 0.64)$ & 0.031 \\
\hline & Constraints related to accessibility & $0.28( \pm 0.49)$ & $0.496( \pm 0.69)$ & 0.000 \\
\hline & Organisational constraints & $0.22( \pm 0.45)$ & $0.24( \pm 0.51)$ & 0.73 \\
\hline & Material constraints & $0.15( \pm 0.44)$ & $0.19( \pm 0.49)$ & 0.37 \\
\hline
\end{tabular}

${ }^{*}$ T test.

Second, almost half (46\%) mentioned the usefulness of specific brochures available for 50 year-olds and over. Consequently, the district newsletter 'The Léonardois', was useful for more than one third $(35.8 \%)$ of respondents. When crossing the results according to the two generations, it was observed that Facebook and the district's website were information channels which were used more by baby boomers than seniors $(\mathrm{p} \leq 0.000)$.

\section{Discussion}

Outdoor activities, such as physical, sports, and nature activities, which were found to be practised a great deal, can be attributed to the variety of green spaces that Saint-Léonard has to offer. The presence of these spaces no doubt contributes to strengthening this attraction for respondents. It was also observed that it is the baby boomers who are most interested by 
outdoor activities. This could be explained by the fact that seniors are more fearful at the thought of practising their hobbies outside, as well as by physical and security considerations. However, these results are consistent with some more general data on attendance and use of the public leisure offer in Quebec. According to several studies, it was noted that outdoor spaces and free practices are more coveted and used by seniors over 50 then indoor and organised activities [21, 22, 23]. As such, Thibault [23] argues, based on a 2008 study, that 58\% of Quebec seniors aged 50 to 65 practise non-competitive, physical recreation, and outdoor activities.

With regard to seniors' physical health, it may be noted that quite a few respondents practise physical and sports activities on a regular basis, as well as outdoor activities related to nature. These results seem to indicate that seniors realise the importance of remaining active for health reasons. This is consistent with several studies, conducted in recent years, which demonstrate that awareness campaigns and the promotion of healthy lifestyles seem to have made an impact on these seniors [24, 25]. In this perspective, the offer of free or spontaneous practice opportunities in this context appears as an important avenue to consider and explore for local actors.

When we focus specifically on the possible gap between seniors and baby boomers, we find that the results of the current study do not agree with those of some studies previously cited. Indeed, it is not possible to distinguish such a strong difference in interests and leisure practices between these two generations, as stated by Beauchamp [17], Sperazza and Banergee [14], and Cochran et al. [13]. Our respondents all seem to attach some importance to nature and outdoor activities as well as physical activities and sports. It is more at the level of constraints that a real difference may be seen, as baby boomers primarily stipulate that there are too many domestic chores, while seniors tend to target those relating to fatigue and shortness of breath, as well as the climate. This analytical finding agrees with Sperazza and Bangergee [14] and Ziegler [19], who state that seniors usually choose leisure activities appropriate to their physical and social realities.

Another notable distinction which emerges between these cohorts regards communication channels useful in transmitting information to these individuals. It may be noted that the baby boomers seem to use and find relevant traditional channels of information (leaflets, brochures, etc.) and other digital sources (social media, websites, etc.). Seniors appear to use or find relevant traditional methods. This analytical observation agrees with the studies by Beauchamp and Marcotte [12] and Fitzpatrick and McCabe [20], who mention that it is fundamental not to consider older customers as a homogeneous population when planning, programming, and promoting leisure offers. This result is also in line with research findings by Roberts [15], Murphy Jr et al. [16], and Ziegler [19], who see the baby-boomer generation as truly turned towards modernity and thus not hesitating to use different means of communication not necessarily designed by and for them.

\section{Conclusions}

Overall, the results obtained and the correlated analyses clearly indicate that the senior population is not homogeneous with respect to their leisure practices and needs. However, some differences reported in the literature between seniors and baby boomers are not clearly reflected in this study, and this is true, among others, with regard to the interests and recrea- tional practices. In the case of the respondents, the differences in this respect seem more related to physical or cultural considerations, even occupational ones, than generational elements. Nevertheless, the results clearly highlight sharp distinctions between these two cohorts in terms of the constraints experienced and informational channels which are deemed useful to learn about the leisure offer being proposed. This analytical finding leads us to partially validate our research hypothesis and to, therefore, confirm that leisure and community services must be planned, programmed, and promoted taking into account these generational differences, as well as the physical, socioeconomic, and cultural differences. Indeed, the results do not highlight major gaps in the leisure service offerings available in the suburb of Saint-Léonard, but show which actions can be taken to better meet the needs of these two generations. As such, the results obtained lead us to formulate some potential intervention ideas. First, it is important to maintain or even improve access to public and outdoor spaces in the district, especially the parks, by developing forms of entertainment specifically aimed at seniors. Complementarily, it would be wise to boost and develop the animation in the parks during the year by offering organised or more, free activities and various forms of assistance to seniors (introductory sessions, support for going from place to place, listening, etc.). In parallel, it seems important to enhance the implementation of leisure as well as free activities that can also be practised individually in the public offer.

To conclude, it is important to mention that this study has some methodological limitations. First, the sample obtained is only statistically representative with regard to all seniors aged 50 years and over residing in Saint-Léonard and not according to gender and certain age levels. In addition, the survey was conducted outdoors and during the summer, which could result in a possible overrepresentation of various types of seniors. Concomitantly, the fact that the questionnaires were administered directly by the investigators, could have caused possible social desirability biases from respondents. Finally, certain realities in the field (low survey participation of seniors over the age of 65, lack of access to some local businesses and other private residences, difficulty reaching the most isolated seniors, etc.) have undoubtedly had a direct impact on the sample obtained.

\section{Literature}

1. Government of Quebec. (2012). Policy: “Ageing and living at home". Québec: Government of Quebec. [in French]

2. Quebec Institute of Statistics. (2014). Demographic perspectives of Quebec and its regions, 2011-2061. Québec: Quebec Institute of Statistics. [in French]

3. World Health Organization (WHO). (2002). Remaining active while ageing: Policy framework. Geneva: WHO. Retrieved April 15, 2016, from http://whqlibdoc.who. int/hq/2002/WHO_NMH_NPH_02.8_fre.pdf?ua=1. [in French]

4. Jackson L.T. (1991). Leisure activities and quality of life. Activities in Action 15(4), 31-36.

5. Kelly J.R., Steinkamp M.W., Kelly J. (1987). Later-life satisfaction: Does leisure contribute? Leisure Sciences 9, 189200.

6. Ragheb M., Griffith C. (1980). The contribution of leisure participation and leisure satisfaction to life satisfaction of older persons. Journal of Leisure Research 14(4), 295-305. 
7. Rousseau J., Denis M.C., Dubé M., Beauchesne M. (1995). Activity, autonomy and well-being of the elderly. Loisir et Société 18(1), 93-122. [in French]

8. Riddick C.C., Daniel S.N. (1984). The relative contribution of leisure activities and other factors to the mental health of older women. Journal of Leisure Research 16(2), 136-148.

9. Agahi N., Silverstein M., Parker M.G. (2011). Late-life and earlier participation in leisure activities: Their importance for survival among older persons. Activities, Adaptation $\mathcal{E}$ Aging 35(3), 210-222.

10. Gibson H., Singleton J. (2012). Leisure and aging: Theory and practice. Champaign, IL: Human Kinetics.

11. Michalos A.C., Zumbo B.D. (2003). Leisure activities, health and the quality of life. In A.C. Michalos (ed.), Essays on the quality of life (pp. 217-238). Dordrecht: Kluwer Academic Publishers.

12. Beauchamp J., Marcotte P. (2014). Leisure and the elderly: Some marketing strategies to promote participation. Bulletin de l'Observatoire Québécois du Loisir 11(9), 1-4. [in French]

13. Cochran L.J., Rothschadl A.M., Rudick J.L. (2009). Leisure programming for baby boomers. Champaign, IL: Human Kinetics.

14. Sperazza L., Banerjee P. (2010). Baby boomers and seniors: Understanding their leisure values enhances programs. Activities, Adaptation \& Aging 34(3), 196-215.

15. Roberts K. (2012). The end of the long baby-boomer generation. Journal of Youth Studies 15(4), 479-497.

16. Murphy Jr E.F., Bahaudin G.M., Manyak T., Sungkhawan J., Greenwood R. (2010). Generational value differences of baby boomers in Thailand. Asia Pacific Business Review 16(4), 545-566.

17. Beauchamp J. (2012). Participative behaviors of the elderly in organized leisure activities and the role of education in leisure and the principles of marketing these services with regard to their participation. Master's paper, University of Quebec in Trois-Rivières. [in French]

18. Kim Y.W., Fidgeon P., Kim J. (2015). Analyzing the leisure activities of the baby boomers and the generation of liberation: Evidence from South Korea. Journal of Tourism and Cultural Change 13(2), 132-148.

19. Ziegler J. (2002). Recreating retirement. How will babyboomers reshape leisure in their 60s? Parks and Recreation 37(10), 56-61.

20. Fitzpatrick T.R., McCabe J. (2008). Future challenges for senior center programming to serve younger and more active baby boomers. Activities, Adaptation \& Aging 32(3/4), 198-213.

21. Carbonneau H. (2011). Portrait of the leisure practices of Quebecers aged 50 and over. Research report. Trois-Rivières: University of Quebec in Trois-Rivières. [in French]

22. SOM. (2003). Satisfaction survey of Montrealers with regard to the supply of municipal sports and leisure services. Montréal: SOM Recherches et Sondages. [in French]

23. Thibault A. (2009). The young elderly give a foretaste of leisure needs and challenges. Bulletin de l'Observatoire Québécois du Loisir 6(9), 1-4. [in French]

24. Ku P.W., Stevinson C., Chen L.J. (2012). Prospective associations between leisure-time physical activity and cognitive performance among older adults across an 11-year period. Journal of Epidemiology 22(3), 230-237.

25. Tortosa-Martinez J., Zoernik D.A., Manchado-Lopez C. (2011). Efficacy of leisure experiences in controlling the onset of dementia in older adults. International Journal on Disability and Human Development 10(2), 103-108.

Submitted: May 9, 2016

Accepted: June 9, 2016 